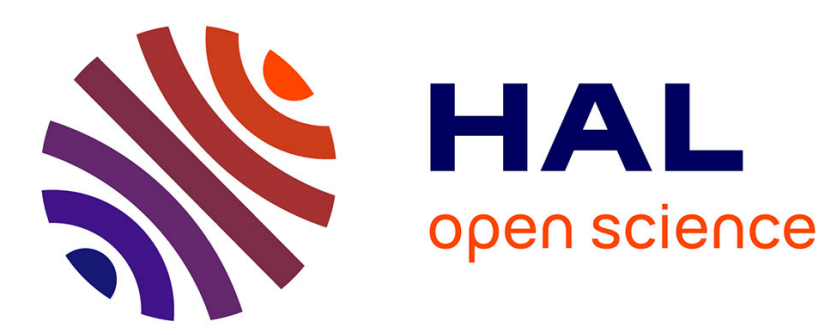

\title{
RADIATIVE, AUGER, AND COSTER-KRONIG YIELDS OBTAINED BY THE SYNCHROTON PHOTOIONIZATION TECHNIQUE
}

U. Werner, W. Jitschin

\section{- To cite this version:}

U. Werner, W. Jitschin. RADIATIVE, AUGER, AND COSTER-KRONIG YIELDS OBTAINED BY THE SYNCHROTON PHOTOIONIZATION TECHNIQUE. Journal de Physique Colloques, 1987, 48 (C9), pp.C9-559-C9-562. 10.1051/jphyscol:1987994 。 jpa-00227415

HAL Id: jpa-00227415

https://hal.science/jpa-00227415

Submitted on 1 Jan 1987

HAL is a multi-disciplinary open access archive for the deposit and dissemination of scientific research documents, whether they are published or not. The documents may come from teaching and research institutions in France or abroad, or from public or private research centers.
L'archive ouverte pluridisciplinaire HAL, est destinée au dépôt et à la diffusion de documents scientifiques de niveau recherche, publiés ou non, émanant des établissements d'enseignement et de recherche français ou étrangers, des laboratoires publics ou privés. 


\title{
RADIATIVE, AUGER, AND COSTER-KRONIG YIELDS OBTAINED BY THE SYNCHROTON PHOTOIONIZATION TECHNIQUE
}

\author{
U. WERNER and W. JITSCHIN* \\ Fakultät für Physik, Universität Bielefeld, D-4800 Bielefeld I, \\ F.R.G. \\ *Phys.-Techn. Bundesanstalt, Institut Berlin, D-1000 Berlin 10, \\ F.R.G.
}

Résumé: Nous avons utilisé une nouvelle technique performante pour mesurer les taux de desexcitation d' atomes lourds ( $72 \leq Z \leq 82$ ) par comblement d'une lacune en couche $L$. Des valeurs des facteurs de Coster-Kronig $f_{23}$ et $f_{13}+f_{12} f_{23}$ sont présentées et discutées.

Abstract: A novel powerful technique was applied to measure L-shell decay yields of heavy elements $(72 \leq Z \leq 82)$. Values of the Coster-Kronig factors $f_{23}$ and $f_{13}+f_{12} f_{23}$ are reported and discussed.

\section{Introduction}

Reliable accurate values of the inner shell yields are required in numerous fields ranging from fundamental research on atomic collision processes [1] to quantitative surface analysis by spectroscopic techniques [2 -4]. Adopted values of L-shell yields [5] partly bear untolerable uncertainties. In particular, for the $\mathrm{L}_{1}$-subshell uncertainties amount to about $20 \%$ which is due to $\mathrm{L}_{1}$-specific problems: experimentally, powerful coincidence techniques are not applicable here [6] and theoretically, the decay is governed by processes with small excess energy [7], where standard calculations [8] fail. Recently, a novel and universal technique for measuring yields of all subshells was introduced which makes use of the subshellselective photoionization with tunable synchroton radiation [9]. In an exploratory measurement this technique has provided stimulating results for $\mathrm{Au}(Z=79)[9,10]$. Comprehensive measurements for a range of elements $72 \leq Z \leq 82$ have been" performed and are now under evaluation. So far, results for Coster-Kronig (CK) factors $f_{23}$ and $f_{13}+f_{12} f_{23}$ are available and are discussed in the present paper. All measurements have been performed at the ROEMO station of the HASYLAB synchroton facility in Hamburg.

\section{Technique}

In the applied novel technique, definitive numbers of vacancies in the individual subshells are produced by photoionization and the $\mathrm{x}$-ray fluorescence emitted in the vacancy decay is detected. The creation of vacancies by photoionization offers essential advantages as compared to vacancy creation by other processes: First, the ionization of a particular subshell can be switched on and off by tuning the energy of the primary photons across its threshold. Second, the cross section of an individual subshell is known with comparatively high accuracy since experimentally it can be directly obtained from x-ray absorption studies and theoretically the photoionization process can be accurately predicted. Our experimental attenuation data (Fig. 1) exhibit a smooth dependence on photon energy $E_{\gamma}$ by a power law; however, they also reveal minor dispersionlike deviations $\Delta\left(E_{\gamma}\right)$. These are due to electron correlation effects which can be partly quantitatively described in the time-dependent local-density approximation [11]. Corresponding calculations reveal that the deviations are quite similar for the different subshells. Therefore, we decided to express the actual ionisation cross sections $\sigma_{L_{i}}^{a c t u a l}$ of the individual L-subshell $i$ by the formula

$$
\sigma_{L_{i}}^{a c t u a l}\left(E_{\gamma}\right)=\sigma_{L_{i}}^{f i t}\left(E_{\gamma}\right)\left[1+\Delta\left(E_{\gamma}\right)\right]
$$

where $\sigma_{L_{i}}^{f i t}$ is an analytical fit to tabulated calculated values [12] and $\Delta$ is a small empirical correction (at most a few percent) which is independent of the subshell and has been determined by matching the theoretical total absorption cross section (sum over all contributing processes) to the experimental $\mathrm{x}$-ray attenuation data (Fig. 1). 
Fig. 1: Photoionization cross section of ${ }_{72} \mathrm{Hf}$ versus photon energy $E_{\gamma}$ in the regime of the L-edges. Curves in the upper part are a theoretical prediction [12]. Dots are experimental data whose absolute values are normalized to theory. The lower part displays the deviation $\Delta$ between experiment and prediction as well as a fitted curve.

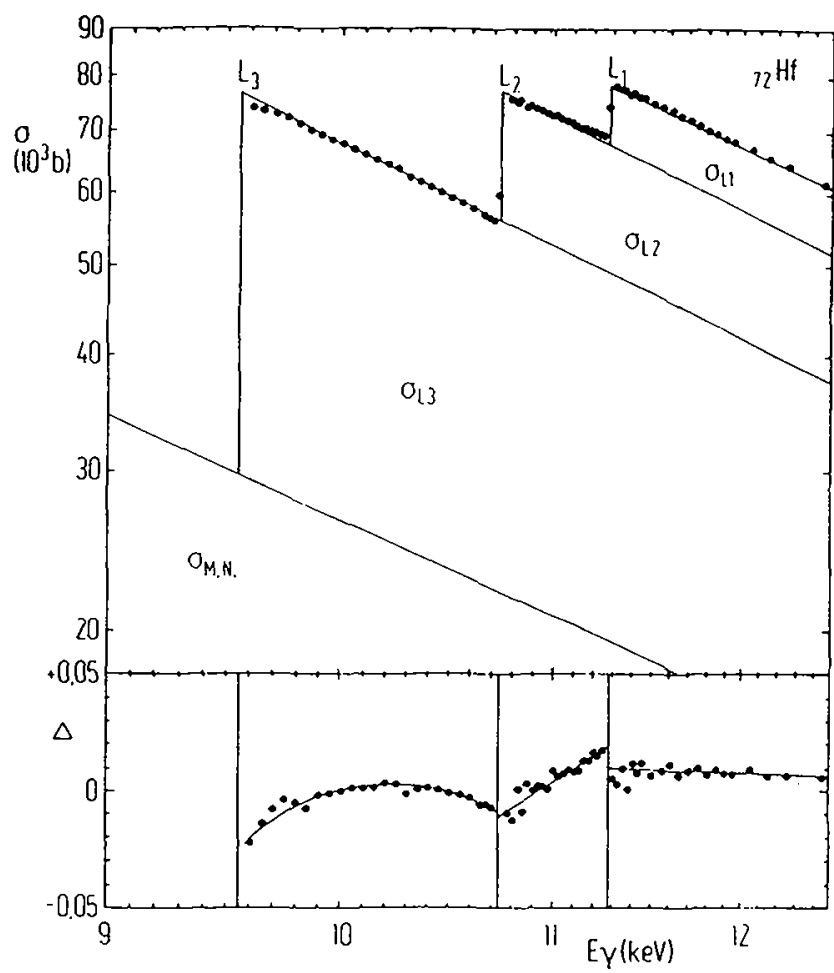

In our technique, the intensity of the $x$-ray fuorescence induced by the photon absorption has to be normalized to the intensity of the primary photons at the various photon energies. This was accomplished by normalization to the $\mathrm{K}-\mathrm{x}$-radiation of a lighter element. For this purpose a sample consisting of two elements was used, e.g. $H f$ and $M n$, and the Hf L-x-rays and the $M n K$ - $x$-rays were simultaneously detected. The $\mathrm{K}$ - $\mathrm{x}$-ray signal is just proportional to the $\mathrm{K}$-shell ionization cross section which in case of $\mathrm{Mn}$ behaves for all $E_{\gamma}$ measured in the present experiment as $\sigma_{K}\left(E_{\gamma}\right) \propto E_{\gamma}^{-2.644}$ as predicted by theory [12] and confirmed by experiment [13].

The L-x-ray spectra show a pronounced energy dependence caused by the onset of the ionization of the individual subshell at their thresholds $E_{L_{i}}$, which allows to determine the fluorescence yields $\omega_{3}$, $\omega_{2}, \omega_{1}$ and the CK factors $f_{23}, f_{12}, f_{13}$. We now specialize to the evaluation of the $L_{\alpha}$-line which bears part of the information: its intensity is proportional to the vacancy creation in the $L_{3}$-subshell, i.e.,

$$
\begin{array}{ll}
\sigma_{L_{3}} & \text { for } E_{L_{3}}<E_{\gamma}<E_{L_{2}} \\
\sigma_{L_{3}}+f_{23} \sigma_{L_{2}} & \text { for } E_{L_{2}}<E_{\gamma}<E_{L_{1}} \\
\sigma_{L_{3}}+f_{23} \sigma_{L_{2}}+\left(f_{13}+f_{12} f_{23}\right) \sigma_{L_{1}} & \text { for } E_{L_{1}}<E_{\gamma}<E_{K}
\end{array}
$$

The first term corresponds to direct $L_{3}$ ionization whereas the other two terms describe a $C K$ vacancy transfer from the $L_{2}$ and $L_{1}$ subshells, respectively. With known ionization cross sections (eq. 1 ) the measured energy dependence of the $L_{\alpha}$-intensity can be fitted (eq. 2). The fits deliver the jumps at the $L_{2}$ and $L_{1}$ absorption edges and thus the $f_{23}$ and $f_{13}+f_{12} f_{23}$ yields. There are minor deviations between the fits omitting the electron correlations $(\Delta \equiv 0)$ and including them. (Fig. 3 ).

\section{s. Results and discussion}

In the following we only consider those yields which have been obtained by fits including electron correlations. Our $f_{23}$ values are compatible with adopted values [5] within the uncertainties, although they are consistently smaller. $f_{23}$ is a parameter which can also be directly measured with a K-x-ray L-x-ray coincidence technique. By this technique $f_{23}(82 P b)=0.112 \pm 0.002$ has been obtained [14]. 
Fig. 2: Intensity of the Hf $L_{\alpha}$ line versus photon energy. Dots are experimental data.' Curves are fits according to eq. 2 using subshell ionization cross sections including (full lines) and omitting (dashed lines) electron correlations.

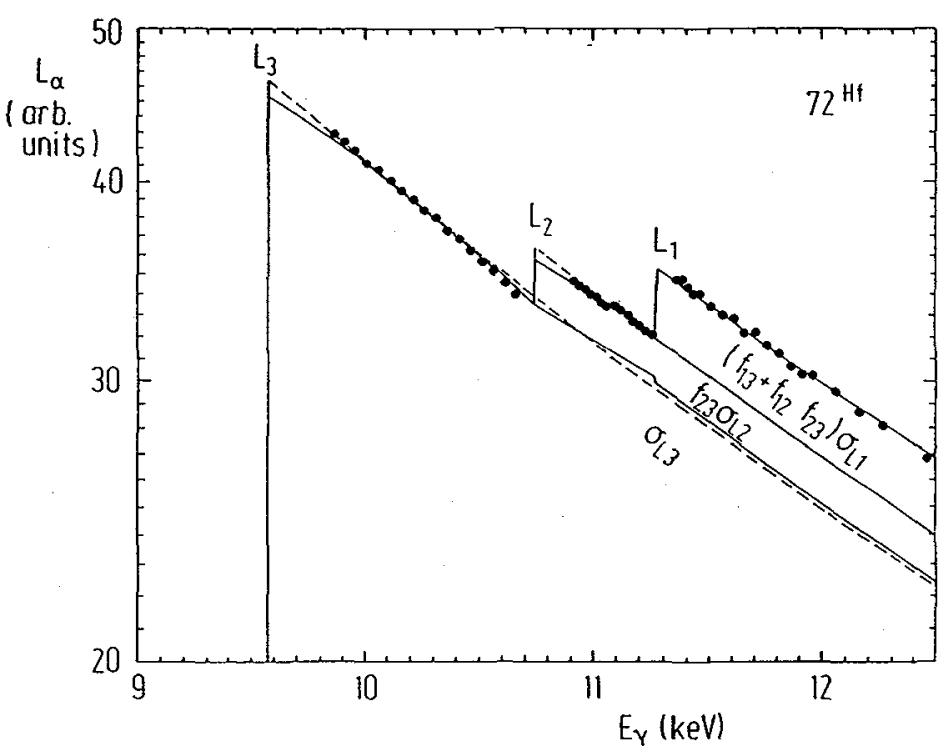

Although the claimed accuracy of $2 \%$ is impressive, we mention that by the same technique $f_{23}(82 P b)=$ $0.130 \pm 0.002$ is reported by another group [1.5]. One crucial problem of these coincidence measurements is the multidimensionality of the coincidence data with a disturbing low-energy tail in the K- $\mathrm{x}$-ray spectrum. This disturbance requires a correction of the measured $f_{23}$ value which amounts to about $30 \%$ of its value. Our method of determining $f_{23}$ is direct; it may suffer from uncertainties in the energydependence of the ionization cross sections caused by electron correlations. Nevertheless we are confident to state the value $f_{23}(82 P b)=0.091 \pm 0.010$.

In the $f_{13}+f_{12} f_{23}$ CK yield the first term is strongly dominant, and it determines the behaviour of the sum. In the investigated range of elements $72 \leq Z \leq 82$ the yield increases by more than a factor of two (Fig. 3 bottom). This increase originates from the increase of $f_{13}$ caused by the onset of the strong $L_{1}-L_{3} M_{4,5} \mathrm{CK}$ channel [8]. Our data lie somewhat above the adopted values [5]. Since (for $Z \geq 76$ ) the procedure of the compilation gives " $f_{1}$ values that are $10-15 \%$ lower than the majority of the measured values" [5], we are in perfect agreement with other experimental work.

In a comparison of our data to theory we make the simplifying approximation, that the $L_{\alpha}$ emission probability is the same if the atom initially has only one $L_{3}$ vacancy (direct ionization) or has an additional spectator vacancy ( $L_{3}$ vacancy production by a Coster-Kronig cascade). Theoretical values of $f_{23}$ [16] are significantly above our experimental ones (Fig. 3). The origin for this discrepancy is not clear; the calculated $f_{23}$ value is dominantly determined by the ratio of the nonradiative decay rates for the processes $L_{2}-L_{3} N(\mathrm{CK})$ and $L_{2}-M_{4,5} M_{4,5}$ (Auger) [8]. Both processes have excess energies of several hundred $\mathrm{eV}$ and should be well predicted by theory. For the $f_{13}+f_{12} f_{23}$ factor the theoretical values lie above the experimental data. This is presumably due to the severe overestimate of the $L_{1}-$ $L_{3} M_{4,5}$ CK transition rate by theory (up to a factor of two) as is known from levelwidth measurements [17] and which is caused by the small excess energy of this transition.

\section{Conclusions}

The applied technique of measuring inner-shell decay yields provides accurate values. Comprehensive work is now required to obtain data for elements with small atomic number, where available data are scarce. This new material will lead to improved adopted values as required in applications and to an improved theoretical understanding of the intrinsic atomic behaviour in a non-equilibrium vacancy state. 
Fig. 3: Coster-Kronig factors $f_{23}$ and $f_{13}+f_{12} f_{23}$. Dots are results of the present work including (full dots) or omitting (open dots) electron correlations. The dashed areas indicate the adopted values with estimated uncertainties [5]; the asterisks denote calculated values [16].

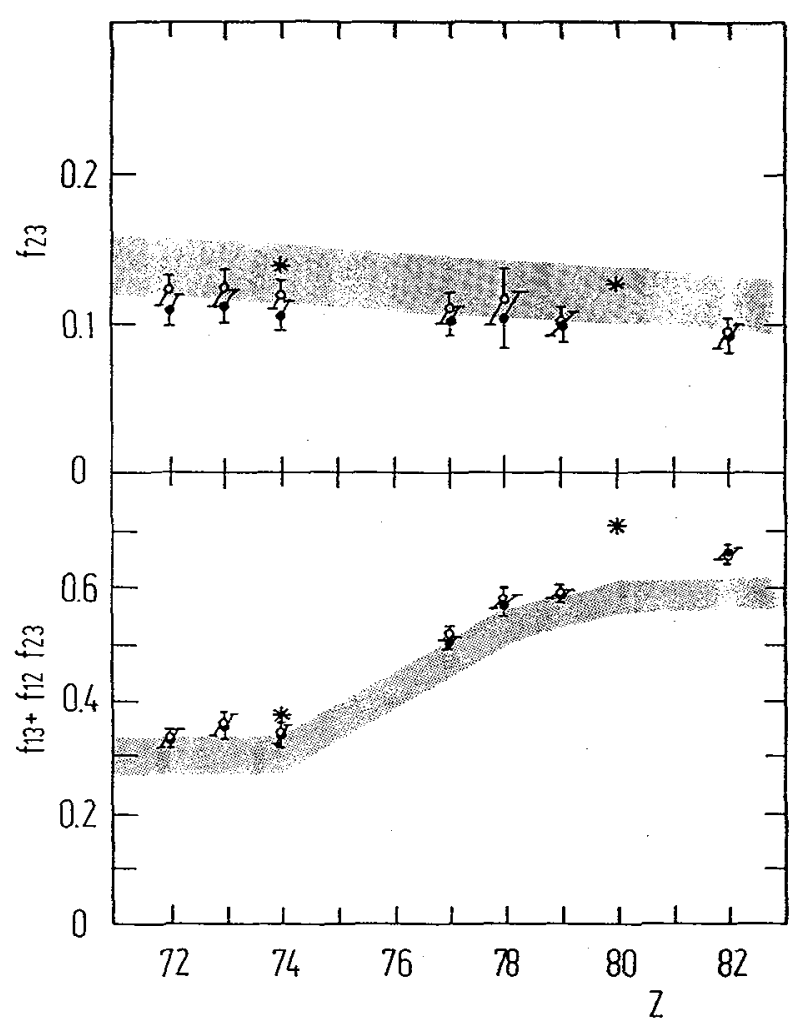

\section{Acknowledgments}

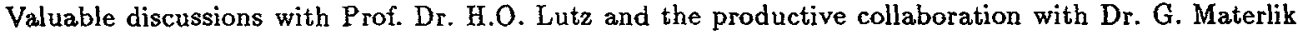
are gratefully acknowledged. This work was supported by the Minister für Wissenschaft und Forschung des Landes Nordrhein-Westfalen.

\section{References}

1 W. Jitschin, Nucl. Instrum. Meth. B4, 292 (1984)

2 C.J. Powell, Proc. 7th Int. Vac. Congr. and 3rd. Int. Conf. Sol. Surf., Vienna (1977) p. 2319

3 M.P. Seah, Vacuum 36, 399 (1986)

4 W. Jitschin and U. Werner, J. Vac. Sci. Technol. A 5, 1203 (1987)

5 M.O. Krause, J. Phys. Chem. Ref. Data 8, 307 (1979)

6 P.V. Rao, in "Atomic Inner-Shell Processes", ed. by B. Crasemann, Academic, New York (1975) p. 1

7 M.H. Chen, B. Crasemann, K.-N. Huang, M. Aoyagi, and H. Mark, At. Data Nucl. Data Tables 19, 97 (1977)

8 M.H. Chen, B. Crasemann, and H. Mark, At. Data Nucl. Data Tables 24, 13 (1979)

9 W. Jitschin, G. Materlik, U. Werner, and P. Funke, J. Phys. B 18, 1139 (1985)

10 W. Jitschin, U. Werner, K. Finck, and H.O. Lutz, in "High-energy ion-atom collisions IT", ed. by D. Berenyi, and G. Hock, Noth-Holland, Amsterdam (1985) p. 79

11 W. Jitschin, U. Werner, G. Materlik, and G.D. Doolen, Phys. Rev. A 35, 5038 (1987)

12 J.H. Scofield, Lawrence Livermore Rad. Lab. Rep. No. UCRL-51326 (1973)

13. J.H. Hubbell and Wm.J. Veigele, NBS Technical Note 901 (1976)

14 J.L. Campbell, P.L. McGhee, R.R. Gingerich, R.W. Ollerhead, and J.A. Maxwell, Phys. Rev. A30, 161 (1984)

15 M. Tan, R.A. Braga, R.W. Fink, and P.V. Rao, Phys. Scr. 25, 536 (1982)

16 M.H. Chen, B. Crasemann, and H. Mark, Phys. Rev. A 24, 177 (1981)

17 O. Keski-Rahkonen, G. Materlik, B. Sonntag, and J. Tulkki, J. Phys. B17, L 121 (1984) 